\title{
Hormone-like (endocrine) Fgfs: their evolutionary history and roles in development, metabolism, and disease
}

\author{
Nobuyuki Itoh
}

Received: 25 May 2010 / Accepted: 14 July 2010 /Published online: 24 August 2010

(C) The Author(s) 2010. This article is published with open access at Springerlink.com

\begin{abstract}
Fibroblast growth factors (Fgfs) are proteins with diverse functions in development, repair, and metabolism. The human Fgf gene family with 22 members can be classified into three groups, canonical, intracellular, and hormone-like $F g f$ genes. In contrast to canonical and intracellular $F g f$ s identified in invertebrates and vertebrates, hormone-like $F g f \mathrm{~s}, F g f 15 / 19, F g f 21$, and $F g f 23$, are vertebrate-specific. The ancestral gene of hormone-like $F g f$ s was generated from the ancestral gene of canonical $\mathrm{Fg} f \mathrm{~s}$ by gene duplication early in vertebrate evolution. Later, Fgf15/19, Fgf21, and $F g f 23$ were generated from the ancestral gene by genome duplication events. Canonical Fgfs act as autocrine/paracrine factors in an Fgf receptor (Fgfr)-dependent manner. In contrast, hormone-like Fgfs act as endocrine factors in an Fgfr-dependent manner. Canonical Fgfs have a heparin-binding site necessary for the stable binding of Fgfrs and local signaling. In contrast, hormone-like $\mathrm{Fgfs}$ acquired endocrine functions by reducing their heparinbinding affinity during their evolution. Fgf15/19 and Fgf23 require $\beta$ Klotho and $\alpha$ Klotho as cofactors, respectively. However, Fgf21 might physiologically require neither. Hormone-like Fgfs play roles in metabolism at postnatal stages, although they also play roles in development at embryonic stages. Fgf15/19 regulates bile acid metabolism in the liver. Fgf21 regulates lipid metabolism in the white adipose tissue. Fgf23 regulates serum phosphate and active
\end{abstract}

This work was supported by a Grant-in-Aid for Scientific Research from the Ministry of Education, Science, Culture and Sports of Japan.

N. Itoh $(\bowtie)$

Department of Genetic Biochemistry, Kyoto University Graduate

School of Pharmaceutical Sciences,

Kyoto, Japan

e-mail: itohnobu@pharm.kyoto-u.ac.jp vitamin D levels. Fgf23 signaling disorders caused by hereditary diseases or tumors result in metabolic disorders. In addition, serum Fgf19 or Fgf21 levels are significantly increased by metabolic disorders. Hormone-like Fgfs are newly emerging and quite unique in their evolution and function.

Keywords Fgf Endocrine - Evolution · Metabolism · Disease

\section{Introduction}

Fibroblast growth factors (Fgfs) are proteins with diverse functions in development, repair, and metabolism. The prototypic Fgfs, Fgfl (acidic Fgf) and Fgf2 (basic Fgf), which were originally isolated as mitogens for fibroblasts from the brain and pituitary, are widely expressed in developing and adult tissues. Fgfs have since been isolated as growth factors for cultured cells or identified by homology-based polymerase chain reaction (PCR) and/ or homology-based searches in DNA databases. A few Fgfs have also been identified in human hereditary diseases or human/mouse tumors (Itoh 2007; Itoh and Ornitz 2008; Krejci et al. 2009; Beenken and Mohammadi 2009).

The human $F g f$ gene family comprises 22 members including Fgfl-Fgf23. Fgfl5 has not been identified in humans. Although the human genome has been completely elucidated, no other member of the human $F g f$ family has been identified. Human Fgfs, which comprise $\sim 150-300$ amino acids, have a conserved $\sim 120$-residue core with $\sim 30$ $60 \%$ identity. Human $F g f$ genes were generated partly by gene duplications early in metazoan evolution but mainly by two large-scale genome duplication events early in vertebrate evolution (Itoh and Ornitz 2004). 
The mouse is a widely used mammal model for studying gene functions. The mouse $F g f$ family also comprises 22 members including $F g f 1-F g f 23$. Fgf19 has not been identified in mice. Fgfl5 and Fgfl9 are orthologs in vertebrates (Itoh and Ornitz 2004). The zebrafish is also a widely used vertebrate model for studying gene functions. The zebrafish Fgf family comprises 28 members with several paralogs generated by an additional genome duplication event shortly after the teleost radiation (Itoh and Konishi 2007; The Zebrafish Model Organism Databases, http://zfin.org).

The $F g f$ family can be divided into seven subfamilies by phylogenetic and gene locus analyses. These subfamilies can also be classified into three groups, the intracellular Fgf11/12/13/14 subfamily, the hormone-like (endocrine) $F g f 19 / 21 / 23$ subfamily, and the canonical $F g f$ subfamily comprising the $F g f 1 / 2 / 5, F g f 3 / 4 / 6, F g f 7 / 10 / 22, F g f 8 / 17 / 18$, and $F g f 9 / 16 / 20$ subfamilies, by their action mechanisms (Itoh and Ornitz 2004, 2008). Canonical Fgfs mediate their biological responses as extracellular proteins by binding to and activating cell surface tyrosine kinase Fgf receptors (Fgfrs) with heparin/heparan sulfate as a cofactor. They act as local signaling molecules in an autocrine/paracrine manner. In the development of multicellular organisms, various signaling pathways are activated in a highly coordinated manner to ensure proper morphogenesis. Secreted signaling molecules such as canonical Fgfs, bone morphogenic proteins (Bmps), Wnts, and Hedgehogs play crucial roles in development by influencing the intracellular signaling events of their neighbors from a distance (Itoh and Ornitz 2004, 2008; Thisse and Thisse 2005; Mikels and Nusse 2006). In contrast, intracellular Fgfs, Fgfl1-Fgf14, act as intracellular signaling molecules in an Fgfrindependent manner. They interact with intracellular domains of voltage-gate sodium channels and with a neuronal mitogen-activated protein kinase scaffold protein, islet-brain-2, and mainly play roles in neuronal functions at postnatal stages (Goldfarb 2005; Goldfarb et al. 2007; Xiao et al. 2007).

Canonical and intracellular $F g f$ s have been identified in invertebrates and vertebrates. However, hormone-like $\mathrm{Fg} f \mathrm{~s}$, $F g f 15 / 19, F g f 21$, and Fgf23, have been identified in vertebrates but not invertebrates (Itoh and Ornitz 2004; Itoh and Konishi 2007). Hormone-like Fgfs also mainly mediate their biological responses in an Fgfr-dependent manner. However, they bind to Fgfrs with quite low affinity even in the presence of heparin/heparan sulfate (Zhang et al. 2006). Hormone-like Fgfs are unique in their evolution and function. Several excellent reviews on the roles of hormone-like Fgfs in metabolism have been published (Fukumoto 2009; Kurosu and Kuro-o 2009; Kharitonenkov 2009; Razzaque 2009). This article provides a review of hormone-like Fgfs, from their evolutionary history to their roles in development, metabolism, and disease.

\section{Identification of hormone-like Fgf genes}

Fgf15/19

$\mathrm{Pbx} 1$ is a homeodomain transcription factor that has the ability to form heterodimers with homeodomain proteins encoded by the homeotic selector (Hox) gene complexes. In pre $\mathrm{B}$ cell leukemias, $\mathrm{Pbx} 1$ is converted into a strong transactivator by fusion to the activation domain of the bHLH transcription factor E2A. The E2A-Pbx1 fusion protein should therefore activate the transcription of genes normally regulated by $\mathrm{Pbx} 1$. Fgfl 15 was originally identified as a downstream target of the chimeric homoedomain oncoprotein E2A-Pbx1 in mice (McWhirter et al. 1997).

A new human $F g f$ was identified by a DNA database search with the conserved amino acid core of known Fgfs. As the human Fgf is not highly similar (less than 55\% amino acid identity) to any other known Fgfs, it was named Fgf19 (Nishimura et al. 1999; Xie et al. 1999). However, the $F g f 19$ gene was later found to be the human ortholog of mouse $F g f 15$ based on conserved synteny around their loci (Itoh and Ornitz 2004). Only the mouse and rat orthologs were named $F g f 15$. The orthologs in other vertebrates were named Fgf19.

Fgf21

Fgf21 was originally identified in mice and humans by homology-based PCR with the conserved amino acid core of human Fgf19 (Nishimura et al. 2000). Later, human Fgf21 was identified as a stimulator of glucose uptake in mouse 3 T3-L1 adipocytes by a glucose uptake assay to search for novel proteins with therapeutic potential to treat diabetes mellitus (Kharitonenkov et al. 2005). Fgf2l was also identified as a gene inducible by fasting or a high-fat, low-carbohydrate ketogenic diet in mice (Inagaki et al. 2007; Badman et al. 2007)

\section{Fgf23}

Fgf 23 was originally identified in mice and humans by a DNA database search with the conserved amino acid core of mouse Fgf15 (Yamashita et al. 2000). Human Fgf23 was simultaneously identified as a gene responsible for autosomal dominant hypophosphatemic rickets (ADHR) (ADHR consortium 2000). ADHR is characterized by low serum phosphate levels, rickets, osteomalacia, lower extremity deformities, short stature, bone pain and dental abscesses. Later, human $F g f 23$ was identified as a causative humoral protein for human tumor-induced osteomalacia (TIO) (Shimada et al. 2001). TIO is a paraneoplasitc disease characterized by hypophosphatemia caused by renal phosphate wasting. 


\section{Identification of the Fgf19/21/23 gene subfamily}

Although Fgf15/19, Fgf21, and Fgf23 are not very similar ( $22-35 \%$ amino acid identity), phylogenetic and gene locus analyses indicate that they are all members of the Fgf19/21/23 subfamily (Itoh and Ornitz 2004, 2008).

\section{Evolutionary history of hormone-like Fgf genes in vertebrates}

The Fgf signaling system has been conserved throughout metazoan evolution. Most ancestral genes of the human $\mathrm{Fgf}$ subfamilies have been identified in the ascidian, Ciona intestinalis. Ascidians belong to the subphylum Urochordata, the earliest branch in the phylum Chordata (Satou et al. 2002). These results indicate that most ancestral genes of the Fgf subfamilies were generated by gene duplication events early in metazoan evolution. The evolutionary history of the Fgf family has been proposed (Fig. 1) (Itoh and Ornitz 2004, 2008). An ancestral gene of the intracellular $F g f$ subfamily, Fgf13-like, is an ancestral gene of the Fgf family. An ancestral gene of the canonical Fgf subfamily, Fgf4-like, was generated from Fgfl3-like by gene duplication during the early stages of metazoan evolution. In contrast, no ancestral gene of the hormone-like Fgf19/21/23 subfamily has been identified in Ciona intestinalis. The ancestral gene, Fgfl9like, was generated from Fgf4-like by local gene duplication early in vertebrate evolution. Later, Fgf19, Fgf21, and Fgf23 were generated from Fgfl9-like by two large-scale genome duplication events (Itoh and Ornitz 2004; Itoh and Ornitz 2008). The evolutionary history suggests that hormone-like $\mathrm{Fg} f \mathrm{~s}$ are vertebrate-specific.

$F g f 15 / 19$ and $F g f 23$ have been identified in all vertebrates examined including teleosts, amphibians, reptiles, birds, and mammals. $F g f 21$ has also been identified in most vertebrates though not birds. Fgf21 might have been lost in the bird lineage (Itoh 2007; Itoh, unpublished observation). Intracellular and canonical Fgf subfamilies have several teleostspecific paralogs, which were generated by an additional teleost-specific genome duplication event, in zebrafish. However, the hormone-like Fgf subfamily has no teleostspecific paralog in zebrafish (Itoh and Konishi 2007). Canonical Fgfs have a heparin-binding site. The site is necessary for the stable binding of Fgfrs and local signaling in an autocrine/paracrine manner. In contrast, hormone-like Fgfs have endocrine functions with reduced heparin-binding affinity (Goetz et al. 2007). Hormonelike Fgfs acquired systemic signaling in an endocrine manner during their evolution (Itoh and Ornitz 2008).

\section{Roles of hormone-like Fgfs in development and metabolism}

Fgf15/19

In mice, the expression of $F g f 15$ exhibits a regionally restricted pattern in the developing nervous system, suggesting that Fgfl5 has roles in regulating cell division and patterning within specific regions of the embryonic brain, spinal cord, and sensory organs (McWhirter et al. 1997). Transgenic mice over-expressing human Fgfl9 showed a significant and specific reduction in fat mass and an increase in energy expenditure, indicating potential roles for Fgf19 in energy metabolism (Tomlinson et al. 2002).

To examine the physiological roles of Fgf15 in vivo, Fgfl 5 knockout mice were generated. The mice survived at a normal Mendelian ratio until embryonic day (E) 10.5, but, then gradually died. Most of them had died by postnatal day (P) 7. Heart defects were observed in the embryonic stages, indicating that Fgf15 is required for proper
Fig. 1 Evolutionary history of the Fgf gene family. Fgf13-like is an ancestral gene of the $F g f$ family. Fgf4-like is an ancestral gene of the canonical Fgf family. Fgf4-like was generated from Fgf13-like by gene duplication. Fgf15/19-like, an ancestral gene of the hormone-like $F g f$ subfamily, was generated from Fgf4-like by local gene duplication early in vertebrate evolution. Later, Fgf15/19, Fgf21, and Fgf23 were generated by two large-scale genome duplication events during the evolution of early vertebrates

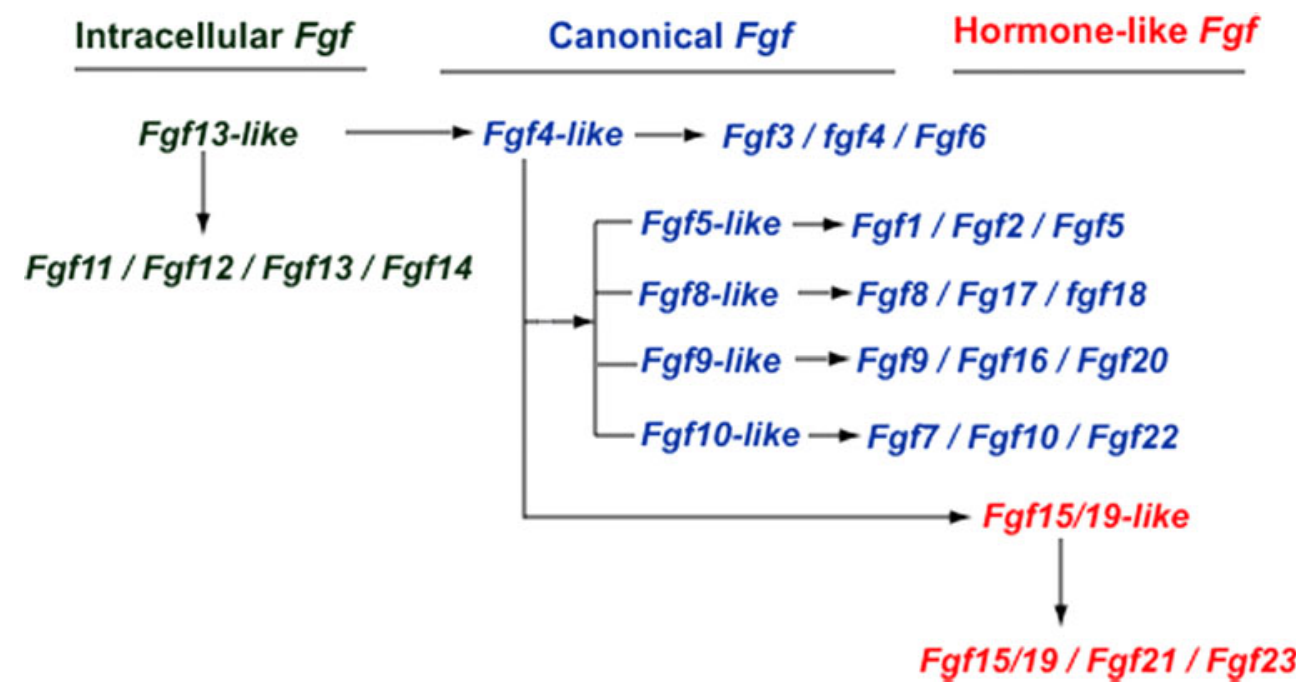


morphogenesis of the cardiac outflow tract during embryonic development (Table 1) (Vincentz et al. 2005). Fgf19 knockdown zebrafish embryos were also generated by the injection of Fgf19 Morpholino antisense oligonucleotides. Their phenotypes show essential roles of Fgf19 in the forebrain, lens, and retina during embryonic development (Table 1) (Miyake et al. 2005; Nakayama et al. 2008). These results indicate that Fgf15/19 acts as a growth/ differentiation factor in the heart and brain at embryonic stages.

Although most Fgf15 knockout mice die by P7, a few survive with a normal appearance. Hepatic cholesterol $7 \alpha$ hydroxylase (Cyp7a1) gene expression is increased in the surviving mice. Cyp7a1 catalyzes the first and rate-limiting step in the classical pathway of bile acid synthesis. Fecal bile acid excretion is increased in Fgfl5 knockout mice (Inagaki et al. 2005). A similar phenotype is observed in Fgfr4 knockout mice (Yu et al. 2000). The liver and intestine play crucial roles in maintaining bile acid homeostasis. Fgfl 5 and Fgfr4 are expressed in the intestine and liver, respectively. These results indicate that intestinal Fgf15 plays a crucial role in regulating hepatic bile acid synthesis at postnatal stages by activating hepatic Fgfr4 in an endocrine manner (Table 1 and Fig. 2) (Inagaki et al. 2005).

\section{Fgf21}

In mice, $F g f 21$ is most abundantly expressed in the liver. $F g f 21$ is also expressed in the pancreas, white adipose tissue, and muscle (Nishimura et al 2000; Kharitonenkov and Shanafelt 2009). Potential roles of Fgf21 in energy metabolism were first shown by experiments in vitro. Fgf21 stimulated glucose uptake in cultured mouse and human adipocytes (Kharitonenkov et al. 2005). The phenotypes of Fgf 21 transgenic mice with over-expression in the liver also indicated potential roles in energy metabolism including improved insulin sensitivity and reduced serum triglycerides levels (Kharitonenkov et al. 2005).

Mammals have evolved complex metabolic responses to fasting. During fasting, nonesterified fatty acid (NEFA) is

Table 1 Roles of hormone-like Fgfs in mice and zebrafish

\begin{tabular}{|c|c|c|}
\hline & Mice & Zebrafish \\
\hline \multicolumn{3}{|c|}{ At embryonic stages } \\
\hline Fgf15/19 & Cardiac outflow development & Brain development \\
\hline Fgf 21 & - & Hematopoiesis \\
\hline Fgf 23 & - & - \\
\hline \multicolumn{3}{|c|}{ At postnatal stages } \\
\hline Fgf15/19 & Bile acid metabolism & - \\
\hline Fgf21 & Lipid metabolism & - \\
\hline Fgf23 & Phosphate/vitamin D metabolism & - \\
\hline
\end{tabular}

released from the white adipose tissue into the liver where it is converted to acetyl-CoA by oxidation. Hepatocytes synthesize ketone bodies from acetyl-CoA. Ketone bodies become the predominant energy source for the brain during fasting. Peroxisome proliferator-activated receptor $\alpha$ $(\operatorname{PPAR} \alpha)$, a nuclear receptor activated by NEFA, is crucial to the normal adaptive response to fasting. Ketogenesis in the liver during fasting is greatly impaired in $P P A R \alpha$ knockout mice (Kersten et al. 1999; Leone et al. 1999). Hepatic $F g f 21$ expression is induced directly by PPAR $\alpha$ in response to fasting. The phenotypes of $F g f 21$ transgenic mice indicate that Fgf21 stimulates lipolysis in the white adipose tissue and ketogenesis in the liver (Inagaki et al. 2007). The expression of $F g f 21$ was also induced in the liver by a high-fat, low-carbohydrate ketogenic diet. In addition, adenoviral knockdown of hepatic Fgf21 in mice fed the ketogenic diet caused reduced serum ketone body levels, fatty liver, and lipemia (Badman et al. 2007). Hepatic triglyceride levels were also significantly decreased in Fgf21 transgenic mice (Inagaki et al. 2007). These results suggest that Fgf21 acts as a metabolic regulator of lipolysis in the white adipose tissue and is required for ketogenesis and triglyceride clearance in the liver.

To elucidate the physiological roles of Fgf21, Fgf 21 knockout mice were generated. The mice were viable, fertile, and seemingly normal. They showed hypertrophy of adipocytes and decreased lipolysis in adipocytes. Serum NEFA levels were significantly decreased, although serum glucose and triglyceride levels were essentially unchanged. In contrast, fasting $F g f 21$ knockout mice showed increased lipolysis in adipocytes and increased serum NEFA levels. These results indicate that Fgf21 stimulates lipolysis in the white adipose tissue during feeding but inhibits it during fasting. Unexpectedly, serum ketone levels were increased by fasting in Fgf 21 knockout mice, indicating that ketogenesis was not impaired (Hotta et al. 2009). These results indicate that Fgf21 regulates lipolysis in adipocytes in response to the metabolic state but is not required for ketogenesis or triglyceride clearance in the liver (Table 1). However, Fgf 21 knockout mice fed a ketogenic diet showed partial impairments in ketogenesis and glucose control (Badman et al. 2009).

Peroxisome proliferation-activated receptor $\gamma$ coactivator$1 \alpha($ Pgc- $1 \alpha)$, a transcriptional coactivator, interacts with several DNA-binding proteins to regulate metabolism in response to changes in nutritional status. Fgf2 1 induces $P g c$ $1 \alpha$ expression in the liver. Fgf21 cannot induce gluconeogenic gene expression in $\mathrm{Pgc}-1 \alpha$ knockout mice. In addition, $F g f 21$ knockout mice did not fully express $P g c-1 \alpha$ in response to prolonged fasting and exhibited impaired glucogenesis and ketogenesis (Potthoff et al. 2009). These results indicate that the metabolic actions of Fgf 21 are mediated in part through Pgc-1 $\alpha$. However, as described above, it 

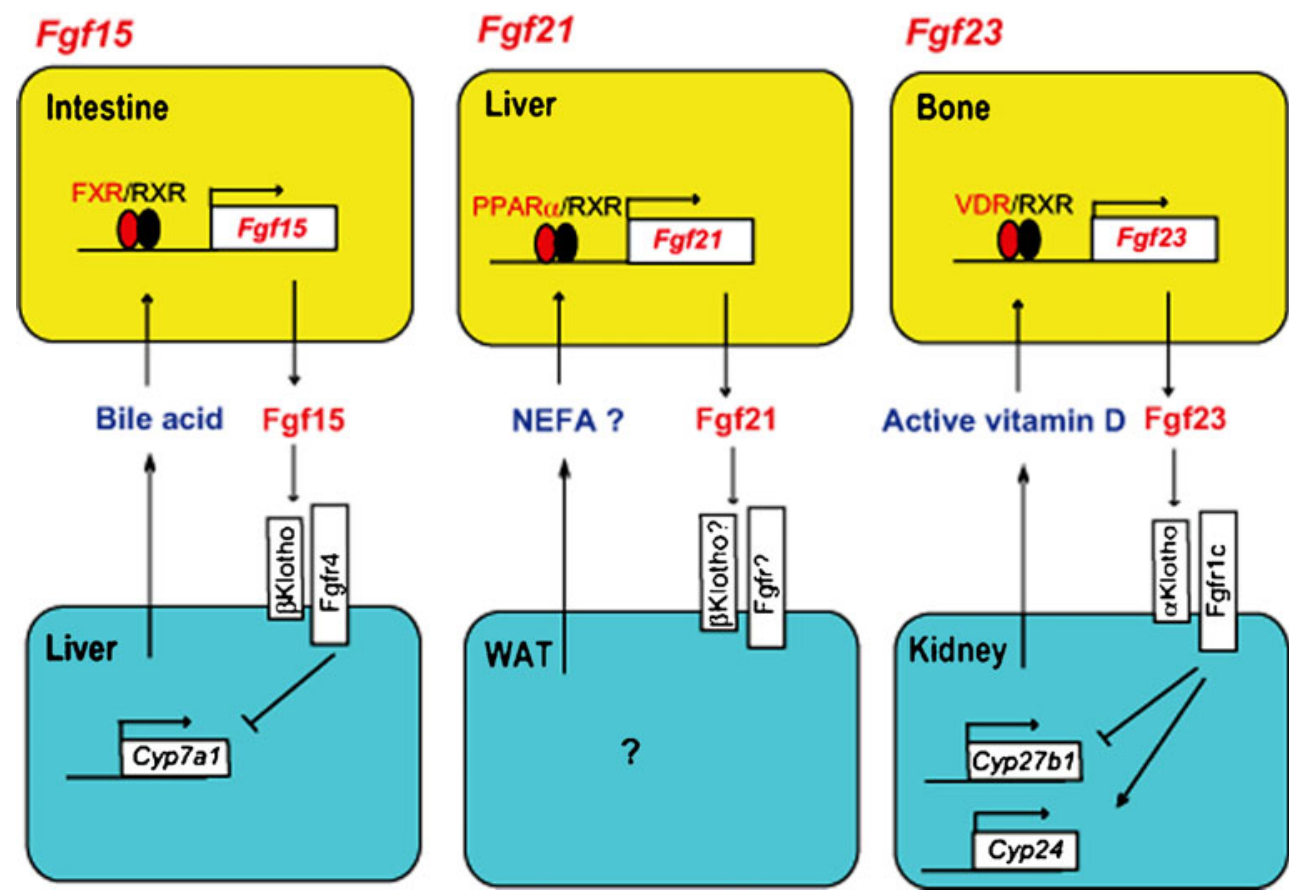

Fig. 2 Action mechanisms of hormone-like Fgfs and regulatory mechanisms of their gene expression. (Fgfl5) Intestinal Fgfl5 expression is regulated by bile acid produced in the liver. The ligand-bound FXR forms a heterodimer with RXRs and induces the expression of $\mathrm{Fgfl5}$. The Fgf15 suppresses the expression of Cyp7al in the liver by activating the $\beta$ Klotho-Fgfr 4 complex. The regulatory process forms a negative feedback loop in the regulation of bile acid homeostasis by Fgf15. ( Fgf21) Hepatic Fgf21 expression is induced by the activation of PPAR $\alpha$. NEFA binds to and activates PPAR $\alpha$.

has also been reported that Fgf21 is not required for glucogenesis and ketogenesis in the liver (Hotta et al. 2009).

Fgf21 regulates the insulin-independent transport of glucose in cultured 3 T3-L1 adipocytes. Functional interplay between the Fgf21 and peroxisome proliferationactivated receptor $\gamma$ (PPAR $\gamma$ ) pathways leads to a marked stimulation of glucose transport (Moyers et al. 2007). These results suggest a novel synergy between Fgf21 and PPAR $\gamma$ homeostasis.

Fgf21 stimulates insulin gene expression but not glucose-induced insulin secretion in isolated rat pancreatic islets. Although Fgf21 has no effect on islet cell proliferation, it preserves $\beta$-cell function and survival (Wente et al. 2006). Fgf 21 expression was markedly increased in mouse pancreatic acinar cells during cerulein-induced pancreatitis and following injury in vitro. Fgf21 transgenic mice exhibited decreased serum amylase levels and decreased pancreatic stellate cell activation. In addition, Fgf21 knockout mice showed increased serum amylase levels and tissue damage (Johnson et al. 2009). These results indicate a function of $\mathrm{Fgfl} 1$ as an immediate response gene protecting pancreatic acini from overt damage.
The ligand-bound PPAR $\alpha$ forms a heterodimer with RXRs and induces the expression of $F g f 21$. However, the regulatory mechanism of $F g f 21$ expression remains unclear. ( $F g f 23$ ) Active vitamin D binds the vitamin $\mathrm{D}$ receptor (VDR). The ligand-bound VDR forms a heterodimer with retinoid $\mathrm{X}$ receptors (RXRs) and induces the expression of $\mathrm{Fgf23}$. The increased Fgf 23 suppresses the expression of Cyp27b1 and induces the expression of Cyp24 by activating the $\alpha$ Klotho-Fgfr 1c complex. The regulatory process forms a negative feedback loop in the regulation of vitamin D homeostasis

Starvation inhibits growth by blocking the growth hormone/insulin-like growth factor I (Igf-I) signaling pathway (Thissen et al. 1999). Fgf21 transgenic mice are 40-50\% smaller than their wild-type counterparts (Inagaki et al. 2008). Fgf21 causes resistance to growth hormone in the liver. Fgf21 reduces concentrations of the active form of signal transducer and activator of transcription 5, a major mediator of growth hormone actions, and causes corresponding decreases in the expression of its target genes including Igf-1. Fgf21 also induces the hepatic expression of genes encoding IGF-1-binding protein 1 and suppressor of cytokine signaling 2, which blunt growth hormone signaling (Inagaki et al. 2008). These results indicate a central role for Fgf21 in inhibiting growth as part of its broader role in inducing the adaptive response to starvation. However, body size and tibia length are essentially unchanged in Fgf 11 knockout mice (Hotta et al 2009). In addition, growth hormone signaling in the liver was essentially unaffected in Fgf 21 knockout mice by normal feeding or fasting for $24 \mathrm{~h}$ (Itoh et al. unpublished observation). These results indicate that Fgf21 is not a major physiological regulator for growth hormone signaling in the liver. 
Torpor, the controlled lowering of metabolic rates, body temperature, and physical activity, is an adaptation that allows various mammals to cope with periods of low food availability (Melvin and Andrews 2009). Fgf21 transgenic mice show torpor-like phenomena such as hypoglycemia, ketosis, and hypothermia (Inagaki et al. 2007). However, fasting-induced hypothermia and locomotor activity were essentially unchanged in $\mathrm{Fg} f 21$ knockout mice (Oishi et al. 2010). These results indicate that Fgf21 is not a major physiological regulator for the hypothermia that is associated with the early stages of fasting.

Fgf 21 knockdown zebrafish embryos were also generated by injection of $F g f 21$ Morpholino antisense oligonucleotides. The embryos lacked erythroid and myeloid cells, indicating that Fgf21 is essential for hematopoiesis in zebrafish. The potential action mechanism of Fgf21 indicates an essential role in hematopoiesis as a differentiation factor (Table 1) (Yamauchi et al. 2006).

Fgf23

Fgf23 is mainly expressed in the bone. Fgf23 decreases serum phosphate levels (Shimada et al. 2004). Type 2a and 2c sodium-phosphate cotransporters ( $\mathrm{NaPi}-2 \mathrm{a}$ and $\mathrm{NaPi}-2 \mathrm{c}$ ) mediate proximal tubular phosphate reabsorption in the kidney. Fgf23 suppresses the expression of $\mathrm{NaPi}-2 a$ and $\mathrm{NaPi}-2 \mathrm{c}$ in proximal tubular cells. Serum phosphate levels are decreased by their suppression. In addition, Fgf23 also suppresses the expression of Cyp27b1 (1 $\alpha$-hydroxylase) and stimulates the expression of Cyp24 (24-hydroxylase). $1 \alpha$-hydrooxylase and 24-hydroxylase mediate the synthesis of active vitamin $\mathrm{D}$ and degrade active vitamin $\mathrm{D}$, respectively. By altering these gene expression levels, Fgf23 decreases levels of active vitamin D in serum. As active vitamin D stimulates intestinal phosphate reabsorption, decreased levels result in decreased serum phosphate levels (Table 1) (Shimada et al. 2004).

To examine the physiological roles of Fgf23 in mice, Fgf23 knockout mice were generated (Shimada et al. 2004). The phenotypes of these mice mirror ADHR and TIO phenotypes. The mice showed hyperphosphatemia and increased active vitamin D levels, indicating that Fgf23 is a physiological regulator for phosphate and active vitamin $\mathrm{D}$ levels in serum.

\section{Action mechanism of hormone-like Fgfs with Klothos}

$\alpha$ Klotho

$\alpha$ Klotho was originally identified as a gene with a lossof-function mutation in a mouse strain that developed multiple aging-like phenotypes (Kuro-o et al. 1997). The phenotypes are essentially similar to those of $F g f 23$ knockout mice (Shimada et al. 2004). These results indicate that Fgf23 and Klotho may function in a common signal transduction pathway. $\alpha$ Klotho is a $130-\mathrm{kDa}$ singlepass transmembrane protein with a short cytoplasmic domain (10 amino acids). The extracellular domain has two homologous domains with sequence similarity to $\beta$ glucosidase. However, $\beta$-glucosidase-like activity is not detected in $\alpha$ Klotho (Kuro-o et al. 1997). In cultured cells, $\alpha$ Klotho efficiently bound to Fgfrs, Fgfr1, and Fgfr3 but not to Fgfr2. $\alpha$ Klotho significantly enhanced the ability of Fgf23 to induce phosphorylation of a substrate of the Fgf receptor and Erk in cultured cells (Kurosu et al. 2006). Alternative splicing in the third immunoglobulin-like domain occurs in Fgfr1, Fgfr2, and Fgfr3 but not in Fgfr4. $\alpha$ Klotho most efficiently binds to and activates Fgfrlc among several isoforms of Fgfrs in cultured cells (Urakawa et al. 2006). These results indicate that Fgf23 activates Fgfr1c, which forms a complex with $\alpha$ Klotho (Fig. 2).

\section{$\beta$ Klotho}

$\beta$ Klotho is a protein that shares structural identity ( $41 \%$ amino acid identity) and characteristics with $\alpha$ Klotho. $\beta$ Klotho is expressed predominantly in the liver, pancreas, and adipose tissue (Ito et al 2000). The synthesis and excretion of bile acids are dramatically increased in $\beta$ Klotho knockout mice. In addition, $\beta$ Klotho knockout mice exhibit resistance to gallstone formation (Ito et al. 2005). Their phenotypes overlap those of Fgfr 4 knockout mice (Yu et al. 2000) and viable $F g f 15$ knockout mice (Inagaki et al. 2005), indicating that Fgf15/19, Fgfr4, and $\beta$ Klotho are essential components in the regulation of bile acid synthesis (Fig. 2). Fgf19 can bind to the $\beta$ Klotho-Fgfr4 complex in cultured cells. Fgf19 also activates Fgf signaling in hepatocytes that primarily express $\mathrm{Fg} f \mathrm{r} 4$ and reduces the expression of Cyp7al encoding the rate-limiting enzyme for bile acid synthesis (Kurosu et al. 2007).

As described above, Fgf15/19 plays roles in development as a growth/differentiation factor (Vincentz et al. 2005; Miyake et al. 2005; Nakayama et al. 2008). However, it remains unclear whether $\beta$ Klotho is required for Fgf15/19 signaling at embryonic stages.

$\beta$ Klotho is also essential for Fgf21 signaling in cultured cells (Ogawa et al. 2007; Kharitonenkov et al. 2008; Suzuki et al. 2008). However, Fgf21 knockout mouse phenotypes (Hotta et al. 2009) are distinct from BKlotho knockout mouse phenotypes (Ito et al. 2005). In addition, administration of recombinant human Fgf21 to $\beta$ Klotho knockout mice indicates that Fgf21 signals are transduced in the absence of $\beta$ Klotho (Tomiyama et al. 2010). These results indicate the existence of a $\beta$ Klothoindependent Fgf21 signaling pathway in which undefined 
cofactors might be involved (Fig. 2). One-to-one functional interactions such as $\alpha$ Klotho/Fgf23, $\beta$ Klotho/ Fgf15/19, and undefined cofactor/Fgf21 would result in tissue-specific signal transduction of the hormone-like Fgf subfamily (Tomiyama et al. 2010). The beneficial pharmacological effects of Fgf21 such as decrease of blood glucose and lipid levels and suppression of weight gain have been observed in mice after its administration or its over-expression by transgene (Kharitonenkov 2009). However, as the pharmacological effects have not been examined in $\beta$ Klotho knockout mice, the involvement of $\beta$ Klotho in the pharmacological effects remains unclear.

\section{Regulatory mechanism of hormone-like Fgf gene expression}

Fgf15

Intestinal $F g f 15$ expression is regulated by bile acid produced in the mouse liver. This bile acid is released into the intestinal lumen and binds to its nuclear receptor, the farnesoid X receptor (FXR), in intestinal epithelial cells. The ligand-bound FXR forms a heterodimer with retinoid X receptors (RXRs) and induces the expression of Fgf15. The Fgf15 suppresses the expression of Cyp $7 a 1$ in the liver by activating Fgfr4. Cyp7a1 catalyzes the rate-limiting step in bile acid synthesis in the liver. The regulatory process forms a negative feedback loop in the regulation of bile acid homeostasis by Fgf15 (Fig. 2) (Inagaki et al. 2005; Kuro-o 2008).

\section{Fgf21}

Hepatic $F g f 21$ expression is greatly induced in wild-type mice but not PPAR $\alpha$ knockout mice by fasting for $24 \mathrm{~h}$. In addition, hepatic $F g f 21$ expression is also greatly induced by GW7647, a PPAR $\alpha$ - selective agonist (Inagaki et al. 2007). These results indicate that hepatic $F g f 21$ expression is induced by the activation of PPAR $\alpha$. NEFA also binds to and activates PPAR $\alpha$. The ligand-bound PPAR $\alpha$ forms a heterodimer with RXRs and induces the expression of $F g f 21$. Fasting increases the amounts of NEFA released from adipocytes. Hepatic $F g f 21$ expression during fasting might be induced through the activation of PPAR $\alpha$ by the NEFA (Moore 2007; Kuro-o 2008). However, although hepatic $F g f 21$ expression is greatly induced in wild-type mice by fasting for $24 \mathrm{~h}$, serum NEFA levels are essentially unchanged (Badman et al. 2007; Hotta et al. 2009). These results indicate that PPAR $\alpha$ is not activated by NEFA during fasting for $24 \mathrm{~h}$. The regulatory mechanism of $F g f 21$ expression remains unclear (Fig. 2).
Fgf23

Active vitamin $\mathrm{D}$ produced in the kidney increases the expression of $\mathrm{Fg} f 23$ in the bone and serum Fgf23 levels in mice. Active vitamin D binds the vitamin D receptor (VDR). The ligand-bound VDR forms a heterodimer with retinoid $\mathrm{X}$ receptors (RXRs) and induces the expression of $F g f 23$ in the bone. The Fgf23 suppresses the expression of Cyp27b1 and induces the expression of Cyp24 in the kidney (Shimada et al 2004). Cyp27b1 and Cyp24 encode enzymes, 1ahydroxylase and 24-hydroxylase, which synthesize and inactivate active vitamin $\mathrm{D}$, respectively. The suppression of Cyp27b1 expression and induction of Cyp24 expression by Fgf 23 result in decreased levels of active vitamin $D$ in serum. The regulatory process forms a negative feedback loop in the regulation of vitamin D homeostasis (Fig. 2) (Tsujikawa et al. 2003; Moore 2007; Kuro-o 2008).

\section{Roles of hormone-like Fgfs in disease}

Fgf19

Serum Fgf19 levels are markedly elevated in patients with extrahepatic cholestasis caused by a pancreatic tumor. Although not expressed in the normal liver, Fgfl9 is abundantly expressed in the liver of cholestatic patients. This is accompanied by a number of adaptations aimed at protecting the liver against bile salt toxicity. Fgf19 signaling may be involved in some of these adaptations (Table 2) (Schaap et al. 2009). Serum Fgf19 levels are also significantly increased in patients on chronic hemodialysis (Table 2) (Reiche et al. 2010). Hepatic lipid metabolism is disturbed in patients with nonalcoholic fatty liver disease (NAFLD). The hepatic response to Fgf19 is impaired in NAFLD patients with insulin resistance. This impaired hepatic response to Fgf19 may contribute to the disturbance of lipid homeostasis in NAFLD (Table 2) (Schreuder et al. 2010).

Fgf21

Serum Fgf21 levels are increased in patients with type 2 diabetes and obesity (Table 2) (Zhang et al 2008; Chen et al 2008; Mraz et al 2009). They are also increased in patients with Cushing's syndrome (Table 2) (Durovcová et al. 2010). In contrast, serum Fgf21 levels are decreased in patients with anorexia nervosa (Table 2) (Dostálová et al. 2008).

\section{Fgf23}

Hereditary Fgf23 signaling disorders result in metabolic disorders (Razzaque 2009). AHDR is caused by missense 
Table 2 Human diseases caused by hormone-like Fgf signaling disorder

\begin{tabular}{|c|c|c|c|}
\hline Gene & Disease & Gene mutation & Fgf signaling \\
\hline \multicolumn{4}{|c|}{ Hereditary disease } \\
\hline \multirow[t]{4}{*}{$F g f 23$} & ADHR & Gain-of-function mutations of $F g f 23$ & Increase \\
\hline & $\mathrm{XLH}$ & Loss-of-function mutations of Phex & Increase \\
\hline & ARHR & Loss-of-function mutations of $\mathrm{Dmpl}$ & Increase \\
\hline & FTC & Loss-of-function mutations of $\mathrm{Fgf} 23$ or Galnt 3 & Decrease \\
\hline \multicolumn{4}{|c|}{ Paraneoplastic disease } \\
\hline Fgf19 & \multicolumn{2}{|c|}{ Extrahepatic cholestasis } & Increase \\
\hline$F g f 23$ & \multicolumn{2}{|c|}{ TIO } & Increase \\
\hline \multicolumn{4}{|c|}{ Metabolic disease } \\
\hline \multirow[t]{2}{*}{ Fgfl } & \multicolumn{2}{|c|}{ Chronic hemodialysis } & Increase \\
\hline & \multicolumn{2}{|c|}{ NAFLD } & Decrease \\
\hline \multirow[t]{4}{*}{$F g f 21$} & \multicolumn{2}{|c|}{ Type 2 diabetes } & Increase \\
\hline & \multicolumn{2}{|c|}{ Obesity } & Increase \\
\hline & \multicolumn{2}{|c|}{ Cushing's syndrome } & Increase \\
\hline & \multicolumn{2}{|c|}{ Anorexia nervosa } & Decrease \\
\hline$F g f 23$ & \multicolumn{2}{|c|}{ Renal failure } & Increase \\
\hline
\end{tabular}

mutations of $F g f 23$ with gain-of-function (ADHR consortium 2000). A part of Fgf23 is cleaved by intracellular proteolytic processing. The cleaved Fgf23 forms lose their biological activity. Fgf23 mutations in ADHR result in impaired proteolytic processing of Fgf 23 and increased active Fgf23 levels in serum (Table 2) (White et al. 2001). Phex encodes endopeptidase. X-linked hypophosphatemia (XLH) is caused by loss-of-function Phex mutations that increase serum Fgf23 levels (Table 2) (Johnson et al. 2009). Dmpl encodes dentin matrix acidic phosphoprotein, an extracellular matrix protein. Autosomal recessive hypophosphatemic rickets/ osteomalacia (ARHR) is caused by loss-of-function Dmpl mutations that increase serum Fgf23 levels (Table 2) (Lorenz-Depiereux et al. 2006). Dmpl knockout mouse phenotypes are similar to ARHR phenotypes. Dmp 1/Fgf23 double knockout mouse phenotypes are similar to $F g f 23$ single knockout mouse phenotypes. These results indicate that the hypophosphatemia in patients with loss-of-function Dmp1 mutations is induced by increased serum Fgf23 levels (Liu et al. 2008). However, the mechanism regulating serum Fgf23 levels has been unclear.

Reduced Fgf23 signaling also causes human metabolic disorders. Familial tumoral calcinosis (FTC) is characterized by ectopic calcification and hyperphosphatemia. Missense mutations of $F g f 23$ with loss-of-function result in FTC. These mutations destabilize the tertiary structure of Fgf23 and increase its susceptibility to degradation (Table 2) (Benet-Pagès et al. 2005). Galnt3 encodes uridine diphosphate-N-acetly- $\alpha$-D-galactosamine: polypeptide $\mathrm{N}$ acetylgalactosaminytransferase. FTC is also caused by lossof-function Galnt3 mutations (Table 2) (Topaz et al. 2004; Frishberg et al. 2005). The enzyme is a Golgi-associated enzyme that initiates mucin-type O-glycosylation at proteins. Fgf23 is glycosylated by Galnt3. The O-glycosylation prevents proteolytic processing of Fgf23 and allows the secretion of an intact Fgf23 (Kato et al. 2006; Frishberg et al. 2007). Galnt3 knockout mice develop hyperphosphatemia without apparent calcification. The loss-of-function mutation of Galnt3 impairs secretion of intact Fgf23, leading to decreased serum Fgf23 levels and hyperphosphatemia (Ichikawa et al. 2009). These results provide in vivo evidence that Galnt3 plays an essential role in the proper secretion of Fgf23.

In addition to hereditary Fgf 23 signaling disorders, tumors that over-produce Fgf23 also cause metabolic disorders. TIO is a paraneoplasitc disease characterized by hypophosphatemia caused by renal phosphate wasting (Table 2) (Shimada et al. 2001). Serum Fgf23 levels are also greatly increased in patients with renal failure, partly owing to decreased renal clearance. These results suggest that Fgf23 to have a compensatory role in the disease (Table 2) (Larsson et al. 2003; Imanishi et al. 2004).

\section{Conclusions}

Hormone-like Fgfs, Fgf15/19, Fgf21, and Fgf23, are newly emerging and unique in evolution and function. Although hormone-like Fgf genes have been identified in most vertebrates examined, they have not been identified in invertebrates, indicating that hormone-like Fgfs are vertebrate-specific. Hormone-like Fgfs mainly act as endocrine factors in an Fgfr-dependent manner. Fgf15/19 and Fgf23 physiologically require $\beta \mathrm{K}$ lotho and $\alpha \mathrm{K}$ lotho and as a 
cofactor, respectively. However, Fgf21 might physiologically require neither. Recent studies have revealed important roles of hormone-like Fgfs in humans, mice, and zebrafish. Hormone-like Fgfs participate in metabolism at postnatal stages, although they also have roles in development at embryonic stages. Fgf15/19 regulates bile acid metabolism in the liver. Fgf21 regulates lipid metabolism in the white adipose tissue. Fgf23 regulates serum phosphate and active vitamin D levels. Hormone-like Fgf signaling disorders caused by hereditary diseases or tumors result in metabolic diseases. In addition, serum hormone-like Fgf levels are significantly affected by some metabolic diseases. Further understanding of the roles of hormone-like Fgfs will provide clues to their roles in metabolism and clinical treatments for metabolic diseases.

Open Access This article is distributed under the terms of the Creative Commons Attribution Noncommercial License which permits any noncommercial use, distribution, and reproduction in any medium, provided the original author(s) and source are credited.

\section{References}

ADHR Consortium (2000) Autosomal dominant hypophosphataemic rickets is associated with mutations in FGF23. Nat Genet 26:345-348

Badman MK, Pissios P, Kennedy AR, Koukos G, Flier JS, MaratosFlier E (2007) Hepatic fibroblast growth factor 21 is regulated by PPARalpha and is a key mediator of hepatic lipid metabolism in ketotic states. Cell Metab 5:426-437

Badman MK, Koester A, Flier JS, Kharitonenkov A, Maratos-Flier E (2009) Fibroblast growth factor 21-deficient mice demonstrate impaired adaptation to ketosis. Endocrinology 150:4931-4940

Beenken A, Mohammadi M (2009) The FGF family: biology, pathophysiology and therapy. Nat Rev Drug Discov 8:235-253

Benet-Pagès A, Orlik P, Strom TM, Lorenz-Depiereux B (2005) An FGF23 missense mutation causes familial tumoral calcinosis with hyperphosphatemia. Hum Mol Genet 14:385-390

Chen WW, Li L, Yang GY, Li K, Qi XY, Zhu W, Tang Y, Liu H, Boden G (2008) Circulating FGF-21 levels in normal subjects and in newly diagnose patients with Type 2 diabetes mellitus. Exp Clin Endocrinol Diabetes 116:65-68

Dostálová I, Kaválková P, Haluzíková D, Lacinová Z, Mráz M, Papezová H, Haluzík M (2008) Plasma concentrations of fibroblast growth factors 19 and 21 in patients with anorexia nervosa. J Clin Endocrinol Metab 3:3627-3632

Durovcová V, Marek J, Hána V, Matoulek M, Zikán V, Haluzíková D, Kaválková P, Lacinová Z, Kršek M, Haluzík M (2010) Plasma concentrations of fibroblast growth factors 21 and 19 in patients with Cushing's syndrome. Physiol Res (in press)

Frishberg Y, Topaz O, Bergman R, Behar D, Fisher D, Gordon D, Richard G, Sprecher E (2005) Identification of a recurrent mutation in GALNT3 demonstrates that hyperostosishyperphosphatemia syndrome and familial tumoral calcinosis are allelic disorders. J Mol Med 83:33-38

Frishberg Y, Ito N, Rinat C, Yamazaki Y, Feinstein S, Urakawa I, Navon-Elkan P, Becker-Cohen R, Yamashita T, Araya K, Igarashi T, Fujita T, Fukumoto S (2007) Hyperostosis-hyperphosphatemia syndrome: a congenital disorder of O-glycosylation associated with augmented processing of fibroblast growth factor 23. J Bone Miner Res 22:235-242

Fukumoto S (2009) The role of bone in phosphate metabolism. Mol Cell Endocrinol 310:63-70

Goetz R, Beenken A, Ibrahimi OA, Kalinina J, Olsen SK, Eliseenkova AV, Xu C, Neubert TA, Zhang F, Linhardt RJ, Yu X, White KE, Inagaki T, Kliewer SA, Yamamoto M, Kurosu H, Ogawa Y, Kuro-o M, Lanske B, Razzaque MS, Mohammadi M (2007) Molecular insights into the klotho-dependent, endocrine mode of action of fibroblast growth factor 19 subfamily members. Mol Cell Biol 27:3417-3428

Goldfarb M (2005) Fibroblast growth factor homologous factors: evolution, structure, and function. Cytokine Growth Factor Rev $16: 215-220$

Goldfarb M, Schoorlemmer J, Williams A, Diwakar S, Wang Q, Huang X, Giza J, Tchetchik D, Kelley K, Vega A, Matthews G, Rossi P, Ornitz DM, D'Angelo E (2007) Fibroblast growth factor homologous factors control neuronal excitability through modulation of voltage-gated sodium channels. Neuron 55:449 463

Hotta Y, Nakamura H, Konishi M, Murata Y, Takagi H, Matsumura S, Inoue K, Fushiki T, Itoh N (2009) Fibroblast growth factor 21 regulates lipolysis in white adipose tissue but is not required for ketogenesis and triglyceride clearance in liver. Endocrinology 150:4625-4633

Ichikawa S, Sorenson AH, Austin AM, Mackenzie DS, Fritz TA, Moh A, Hui SL, Econs MJ (2009) Ablation of the Galnt3 gene leads to low-circulating intact fibroblast growth factor 23 (Fgf23) concentrations and hyperphosphatemia despite increased Fgf23 expression. Endocrinology 150:2543-2550

Imanishi Y, Inaba M, Nakatsuka K, Nagasue K, Okuno S, Yoshihara A, Miura M, Miyauchi A, Kobayashi K, Miki T, Shoji T, Ishimura E, Nishizawa Y (2004) FGF-23 in patients with endstage renal disease on hemodialysis. Kidney Int 65:1943-1946

Inagaki T, Choi M, Moschetta A, Peng L, Cummins CL, McDonald JG, Luo G, Jones SA, Goodwin B, Richardson JA, Gerard RD, Repa JJ, Mangelsdorf DJ, Kliewer SA (2005) Fibroblast growth factor 15 functions as an enterohepatic signal to regulate bile acid homeostasis. Cell Metab 2:217-225

Inagaki T, Dutchak P, Zhao G, Ding X, Gautron L, Parameswara V, Li Y, Goetz R, Mohammadi M, Esser V, Elmquist JK, Gerard RD, Burgess SC, Hammer RE, Mangelsdorf DJ, Kliewer SA (2007) Endocrine regulation of the fasting response by PPARalphamediated induction of fibroblast growth factor 21. Cell Metab $5: 415-425$

Inagaki T, Lin VY, Goetz R, Mohammadi M, Mangelsdorf DJ, Kliewer SA (2008) Inhibition of growth hormone signaling by the fasting-induced hormone FGF21. Cell Metab 8:77-83

Ito S, Kinoshita S, Shiraishi N, Nakagawa S, Sekine S, Fujimori T, Nabeshima YI (2000) Molecular cloning and expression analyses of mouse betaklotho, which encodes a novel Klotho family protein. Mech Dev 98:115-119

Ito S, Fujimori T, Furuya A, Satoh J, Nabeshima Y, Nabeshima Y (2005) Impaired negative feedback suppression of bile acid synthesis in mice lacking betaKlotho. J Clin Invest 115:22022208

Itoh N (2007) The Fgf families in humans, mice, and zebrafish: their evolutional processes and roles in development, metabolism, and disease. Biol Pharm Bull 30:1819-1825

Itoh N, Konishi M (2007) The zebrafish fgf family. Zebrafish 4:179-186

Itoh N, Ornitz DM (2004) Evolution of the Fgf and Fgfr gene families. Trends Genet 20:563-569

Itoh N, Ornitz DM (2008) Functional evolutionary history of the mouse Fgf gene family. Dev Dyn 237:18-27

Johnson CL, Weston JY, Chadi SA, Fazio EN, Huff MW, Kharitonenkov A, Köester A, Pin CL (2009) Fibroblast growth factor 21 reduces the 
severity of cerulein-induced pancreatitis in mice. Gastroenterology 137:1795-1804

Kato K, Jeanneau C, Tarp MA, Benet-Pagès A, Lorenz-Depiereux B, Bennett EP, Mandel U, Strom TM, Clausen H (2006) Polypeptide GalNAc-transferase T3 and familial tumoral calcinosis. Secretion of fibroblast growth factor 23 requires O-glycosylation. J Biol Chem 281:18370-18377

Kersten S, Seydoux J, Peters JM, Gonzalez FJ, Desvergne B, Wahli W (1999) Peroxisome proliferator-activated receptor alpha mediates the adaptive response to fasting. J Clin Invest 103:1489-1498

Kharitonenkov A (2009) FGFs and metabolism. Curr Opin Pharmacol 9:805-810

Kharitonenkov A, Shanafelt AB (2009) FGF21: a novel prospect for the treatment of metabolic diseases. Curr Opin Investig Drugs 10:359-364

Kharitonenkov A, Shiyanova TL, Koester A, Ford AM, Micanovic R, Galbreath EJ, Sandusky GE, Hammond LJ, Moyers JS, Owens RA, Gromada J, Brozinick JT, Hawkins ED, Wroblewski VJ, Li DS, Mehrbod F, Jaskunas SR, Shanafelt AB (2005) FGF-21 as a novel metabolic regulator. J Clin Invest 115:1627-1635

Kharitonenkov A, Dunbar JD, Bina HA, Bright S, Moyers JS, Zhang C, Ding L, Micanovic R, Mehrbod SF, Knierman MD, Hale JE, Coskun T, Shanafelt AB (2008) FGF-21/FGF-21 receptor interaction and activation is determined by betaKlotho. J Cell Physiol 215:1-7

Krejci P, Prochazkova J, Bryja V, Kozubik A, Wilcox WR (2009) Molecular pathology of the fibroblast growth factor family. Hum Mutat 30:1245-1255

Kuro-o M (2008) Endocrine FGFs and Klothos: emerging concepts. Trends Endocrinol Metab 19:239-245

Kuro-o M, Matsumura Y, Aizawa H, Kawaguchi H, Suga T, Utsugi T, Ohyama Y, Kurabayashi M, Kaname T, Kume E, Iwasaki H, Iida A, Shiraki-Iida T, Nishikawa S, Nagai R, Nabeshima YI (1997) Mutation of the mouse klotho gene leads to a syndrome resembling ageing. Nature 390:45-51

Kurosu H, Kuro-o M (2009) Endocrine fibroblast growth factors as regulators of metabolic homeostasis. Biofactors 35:52-60

Kurosu H, Ogawa Y, Miyoshi M, Yamamoto M, Nandi A, Rosenblatt KP, Baum MG, Schiavi S, Hu MC, Moe OW, Kuro-o M (2006) Regulation of fibroblast growth factor-23 signaling by klotho. J Biol Chem 281:6120-6123

Kurosu H, Choi M, Ogawa Y, Dickson AS, Goetz R, Eliseenkova AV, Mohammadi M, Rosenblatt KP, Kliewer SA, Kuro-o M (2007) Tissue-specific expression of betaKlotho and fibroblast growth factor (FGF) receptor isoforms determines metabolic activity of FGF19 and FGF21. J Biol Chem 282:26687-26695

Larsson T, Nisbeth U, Ljunggren O, Jüppner H, Jonsson KB (2003) Circulating concentration of FGF-23 increases as renal function declines in patients with chronic kidney disease, but does not change in response to variation in phosphate intake in healthy volunteers. Kidney Int 64:2272-2279

Leone TC, Weinheimer CJ, Kelly DP (1999) A critical role for the peroxisome proliferator-activated receptor alpha (PPARalpha) in the cellular fasting response: the PPARalpha-null mouse as a model of fatty acid oxidation disorders. Proc Natl Acad Sci USA 96:7473-7478

Liu S, Zhou J, Tang W, Menard R, Feng JQ, Quarles LD (2008) Pathogenic role of Fgf23 in Dmp1-null mice. Am J Physiol Endocrinol Metab 295:E254-E261

Lorenz-Depiereux B, Bastepe M, Benet-Pagès A, Amyere M, Wagenstaller J, Müller-Barth U, Badenhoop K, Kaiser SM, Rittmaster RS, Shlossberg AH, Olivares JL, Loris C, Ramos FJ, Glorieux F, Vikkula M, Jüppner H, Strom TM (2006) DMP1 mutations in autosomal recessive hypophosphatemia implicate a bone matrix protein in the regulation of phosphate homeostasis. Nat Genet 38:1248-1250
McWhirter JR, Goulding M, Weiner JA, Chun J, Murre C (1997) A novel fibroblast growth factor gene expressed in the developing nervous system is a downstream target of the chimeric homeodomain oncoprotein E2A-Pbx1. Development 124:3221-3232

Melvin RG, Andrews MT (2009) Torpor induction in mammals: recent discoveries fueling new ideas. Trends Endocrinol Metab 20:490-498

Mikels AJ, Nusse R (2006) Wnts as ligands: processing, secretion and reception. Oncogene 25:7461-7468

Miyake A, Nakayama Y, Konishi M, Itoh N (2005) Fgf19 regulated by $\mathrm{Hh}$ signaling is required for zebrafish forebrain development. Dev Biol 288:259-275

Moore DD (2007) Physiology. Sister act. Science 316:1436-1438

Moyers JS, Shiyanova TL, Mehrbod F, Dunbar JD, Noblitt TW, Otto KA, Reifel-Miller A, Kharitonenkov A (2007) Molecular determinants of FGF-21 activity-synergy and cross-talk with PPARgamma signaling. J Cell Physiol 210:1-6

Mraz M, Bartlova M, Lacinova Z, Michalsky D, Kasalicky M, Haluzikova D, Matoulek M, Dostalova I, Humenanska V, Haluzik M (2009) Serum concentrations and tissue expression of a novel endocrine regulator fibroblast growth factor- 21 in patients with type 2 diabetes and obesity. Clin Endocrinol 71:369-375

Nakayama Y, Miyake A, Nakagawa Y, Mido T, Yoshikawa M, Konishi M, Itoh N (2008) Fgf19 is required for zebrafish lens and retina development. Dev Biol 313:752-766

Nishimura T, Utsunomiya Y, Hoshikawa M, Ohuchi H, Itoh N (1999) Structure and expression of a novel human FGF, FGF-19, expressed in the fetal brain. Biochim Biophys Acta 1444:148 151

Nishimura T, Nakatake Y, Konishi M, Itoh N (2000) Identification of a novel FGF, FGF-21, preferentially expressed in the liver. Biochim Biophys Acta 492:203-206

Ogawa Y, Kurosu H, Yamamoto M, Nandi A, Rosenblatt KP, Goetz R, Eliseenkova AV, Mohammadi M, Kuro-o M (2007) BetaKlotho is required for metabolic activity of fibroblast growth factor 21 . Proc Natl Acad Sci USA 104:7432-7437

Oishi K, Sakamoto K, Konishi M, Murata Y, Itoh N, Sei H (2010) FGF21 is dispensable for hypothermia induced by fasting in mice. Neuro Endocrinol Lett 31:198-202

Potthoff MJ, Inagaki $T$, Satapati S, Ding X, He T, Goetz R, Mohammadi M, Finck BN, Mangelsdorf DJ, Kliewer SA, Burgess SC (2009) FGF21 induces PGC-1alpha and regulates carbohydrate and fatty acid metabolism during the adaptive starvation response. Proc Natl Acad Sci USA 106:10853-10858

Razzaque MS (2009) The FGF23-Klotho axis: endocrine regulation of phosphate homeostasis. Nat Rev Endocrinol 5:611-619

Reiche M, Bachmann A, Lössner U, Blüher M, Stumvoll M, Fasshauer M (2010) Fibroblast growth factor 19 serum levels: relation to renal function and metabolic parameters. Horm Metab Res 42:178-181

Satou Y, Imai KS, Satoh N (2002) Fgf genes in the basal chordate Ciona intestinalis. Dev Genes Evol 212:432-438

Schaap FG, van der Gaag NA, Gouma DJ, Jansen PL (2009) High expression of the bile salt-homeostatic hormone fibroblast growth factor 19 in the liver of patients with extrahepatic cholestasis. Hepatology 49:1228-1235

Schreuder TC, Marsman HA, Lenicek M, van Werven JR, Nederveen AJ, Jansen PL, Schaap FG (2010) The hepatic response to FGF19 is impaired in patients with nonalcoholic fatty liver disease and insulin resistance. Am J Physiol Gastrointest Liver Physiol 298:G440-G445

Shimada T, Mizutani S, Muto T, Yoneya T, Hino R, Takeda S, Takeuchi Y, Fujita T, Fukumoto S, Yamashita T (2001) Cloning and characterization of FGF23 as a causative factor of tumorinduced osteomalacia. Proc Natl Acad Sci USA 98:6500-6505 
Shimada T, Kakitani M, Yamazaki Y, Hasegawa H, Takeuchi Y, Fujita T, Fukumoto S, Tomizuka K, Yamashita T (2004) Targeted ablation of Fgf23 demonstrates an essential physiological role of FGF23 in phosphate and vitamin D metabolism. J Clin Invest 113:561-568

Suzuki M, Uehara Y, Motomura-Matsuzaka K, Oki J, Koyama Y, Kimura M, Asada M, Komi-Kuramochi A, Oka S, Imamura T (2008) betaKlotho is required for fibroblast growth factor (FGF) 21 signaling through FGF receptor (FGFR) 1c and FGFR3c. Mol Endocrinol 22:1006-1014

Thisse B, Thisse C (2005) Functions and regulations of fibroblast growth factor signaling during embryonic development. Dev Biol 287:390-402

Thissen JP, Underwood LE, Ketelslegers JM (1999) Regulation of insulin-like growth factor-I in starvation and injury. Nutr Rev 57:167-176

Tomiyama K, Maeda R, Urakawa I, Yamazaki Y, Tanaka T, Ito S, Nabeshima Y, Tomita T, Odori S, Hosoda K, Nakao K, Imura A, Nabeshima Y (2010) Relevant use of Klotho in FGF19 subfamily signaling system in vivo. Proc Natl Acad Sci USA 107:16661671

Tomlinson E, Fu L, John L, Hultgren B, Huang X, Renz M, Stephan JP, Tsai SP, Powell-Braxton L, French D, Stewart TA (2002) Transgenic mice expressing human fibroblast growth factor-19 display increased metabolic rate and decreased adiposity. Endocrinology 143:1741-1747

Topaz O, Shurman DL, Bergman R, Indelman M, Ratajczak P, Mizrachi M, Khamaysi Z, Behar D, Petronius D, Friedman V, Zelikovic I, Raimer S, Metzker A, Richard G, Sprecher E (2004) Mutations in GALNT3, encoding a protein involved in O-linked glycosylation, cause familial tumoral calcinosis. Nat Genet 36:579-581

Tsujikawa H, Kurotaki Y, Fujimori T, Fukuda K, Nabeshima Y (2003) Klotho, a gene related to a syndrome resembling human premature aging, functions in a negative regulatory circuit of vitamin D endocrine system. Mol Endocrinol 17:2393-2403

Urakawa I, Yamazaki Y, Shimada T, Iijima K, Hasegawa H, Okawa K, Fujita T, Fukumoto S, Yamashita T (2006) Klotho converts canonical FGF receptor into a specific receptor for FGF23. Nature 444:770-774
Vincentz JW, McWhirter JR, Murre C, Baldini A, Furuta Y (2005) Fgf15 is required for proper morphogenesis of the mouse cardiac outflow tract. Genesis 41:192-201

Wente W, Efanov AM, Brenner M, Kharitonenkov A, Köster A, Sandusky GE, Sewing S, Treinies I, Zitzer H, Gromada J (2006) Fibroblast growth factor-21 improves pancreatic betacell function and survival by activation of extracellular signalregulated kinase $1 / 2$ and Akt signaling pathways. Diabetes 55:2470-2478

White KE, Carn G, Lorenz-Depiereux B, Benet-Pages A, Strom TM, Econs MJ (2001) Autosomal-dominant hypophosphatemic rickets (ADHR) mutations stabilize FGF-23. Kidney Int 60:20792086

Xiao M, Xu L, Laezza F, Yamada K, Feng S, Ornitz DM (2007) Impaired hippocampal synaptic transmission and plasticity in mice lacking fibroblast growth factor 14. Mol Cell Neurosci 34:366-377

Xie MH, Holcomb I, Deuel B, Dowd P, Huang A, Vagts A, Foster J, Liang J, Brush J, Gu Q, Hillan K, Goddard A, Gurney AL (1999) FGF-19, a novel fibroblast growth factor with unique specificity for FGFR4. Cytokine11:729-735

Yamashita T, Yoshioka M, Itoh N (2000) Identification of a novel fibroblast growth factor, FGF-23, preferentially expressed in the ventrolateral thalamic nucleus of the brain. Biochem Biophys Res Commun 277:494-498

Yamauchi H, Hotta Y, Konishi M, Miyake A, Kawahara A, Itoh N (2006) Fgf21 is essential for haematopoiesis in zebrafish. EMBO Rep 7:649-654

Yu C, Wang F, Kan M, Jin C, Jones RB, Weinstein M, Deng CX, McKeehan WL (2000) Elevated cholesterol metabolism and bile acid synthesis in mice lacking membrane tyrosine kinase receptor FGFR4. J Biol Chem 275:15482-15489

Zhang X, Ibrahimi OA, Olsen SK, Umemori H, Mohammadi M, Ornitz DM (2006) Receptor specificity of the fibroblast growth factor family. The complete mammalian FGF family. J Biol Chem 281:15694-15700

Zhang X, Yeung DC, Karpisek M, Stejskal D, Zhou ZG, Liu F, Wong RL, Chow WS, Tso AW, Lam KS, Xu A (2008) Serum FGF21 levels are increased in obesity and are independently associated with the metabolic syndrome in humans. Diabetes 57:1246-1253 